\title{
Developing Comprehensive Diabetes Education Materials for Structured Patient Education Programs in Primary Care Setting
}

\author{
Oryzati Hilman Agrimon ${ }^{1}$, Jackie Street ${ }^{2}$ \\ ${ }^{1}$ Department of Family Medicine and Public Health, School of Medicine, \\ Faculty of Medicine and Health Sciences, Universitas Muhammadiyah Yogyakarta, Indonesia \\ ${ }^{2}$ Discipline of Public Health, School of Population Health \& Clinical Practice, Faculty of Health Sciences, \\ University of Adelaide, Australia
}

\section{Article Info \\ Article history: \\ Received Aug 25, 2015 \\ Revised Feb 20, 2016 \\ Accepted Feb 26, 2016}

\section{Keyword:}

Comprehensive diabetes education materials Diabetes leaflets Primary care Stuctured diabetes education program

\begin{abstract}
Diabetes education is a key factor for a succesful diabetes care. Comprehensive diabetes education materials for conducting stuctured diabetes education programs were rarely found in primary care setting in Indonesia. There was a need for developing new, comprehensive diabetes education materials for low-literate readers. Developing these education materials followed standard steps in developing print materials, and took account tips for writing low literacy materials for poor readers. The new diabetes education materials consisted of tenvarious leaflets, also printed as 14 posters and $14 \mathrm{x}$-banners. The ten diabetes leaflets were pre-tested to 5 people with type 2 diabetes (T2D). After minor revisions, the leaflets were printed and distributed to 88 people with T2D attending two structured diabetes education programs in Yogyakarta City. These 88 people were requested to evaluate the leaflets using an evaluation form consisting of four items on language usage, font size, use of pictures, and diabetes informationwith a 1-10 rating scale; and an open-ended question for improvement. Descriptive statistics were used to analyze the results. Most participants thought that the leaflets were easy to understand and read, interesting, and simple. Majority of participants (79.7\%) gave favorable comments without providing suggestions for improvement, such as: "The diabetes leaflets are already good and easy to understand". One third of the participants gave suggestions for improvement. The comprehensive diabetes leaflets developed were well received and highly appreciated by people with $\mathrm{T} 2 \mathrm{D}$ attending diabetes education programs.
\end{abstract}

Copyright $@ 2016$ Institute of Advanced Engineering and Science. All rights reserved.

\section{Corresponding Author:}

Oryzati Hilman-Agrimon,

Department of Family Medicine and Public Health, School of Medicine,

Faculty of Medicine and Health Sciences, Universitas Muhammadiyah Yogyakarta,

Jl. Lingkar Selatan, Kasihan, Bantul, Yogyakarta 55183, Indonesia.

E-mail: oryzatih@yahoo.com

\section{INTRODUCTION}

Diabetes has become a growing public health problem as estimates and projections continue to indicate a 'diabetes epidemic' worldwide. This is due to population growth, aging, urbanization, and particularly increasing prevalence of obesity, decreasing levels of physical activity and adoption of other unhealthy lifestyles. Diabetes is a life-threatening condition. It can cause devastating complications silently developed, sometimes even without being realized by the sufferers and eventually lead to deaths, thus largely 
known as a 'silent killer' disease. Globally, more than 170 million people suffered from diabetes in 2000, a number projected to double to 366 million by the year 2030 [1]-[3].

The World Health Organization (WHO) suggests that the escalation in diabetes in developing nations is particularly alarming since developing nations contribute approximately $75 \%$ of the global diabetes burden [4]. This includes Indonesia. In a 2004 study on Global Prevalence of Diabetes, Indonesia is listed the fourth amongst the top ten countries with the highest numbers of estimated diabetes cases after India, China, and USA. Diabetes cases in Indonesia are projected to increase from 8.4 million in 2000 to 21.3 million in $2030[2]$.

As a complex and progressive chronic condition, diabetes requires both high quality clinical care and effective self-management. Diabetes self-management education (DSME) is increasingly recognized as a central component of diabetes care. According to Tang et al., the focus of DSME is to help patients acquire the knowledge, information, self-care practices, coping skills, and attitudes required to self-manage their diabetes effectively [5],[6].

The recommendations in Australian National Evidence Based Guideline for Patient Education in Type 2 Diabetes 2009 indicate that diabetes structured patient education, delivered in groups or individually, should be provided to all people with type 2 diabetes (T2D) [7]. According to Loveman et al., the purpose of patient education for people with $\mathrm{T} 2 \mathrm{D}$ is to empower patients by improving knowledge, skills and confidence, enabling them to take increasing control of their condition [8].

Funnel et al. suggests that the traditional model of diabetes education has been ineffective in bringing about the desired outcomes [9]. According to Goldstein, self-management education approaches signify involving patient judgment and values within the context of daily living to inform how a comprehensive treatment plan can be best agreed and implemented. Therefore, the American and British Diabetes Associations have referred to diabetes education as diabetes self-management education [10]. However, more than $50 \%$ of patients with diabetes receive limited diabetes self-management education, or none [11],[12].

Providing comprehensive information on T2D in an interesting and engaging way is essential to enable people with T2D learn well about the disease. Using easy-to-read written patient educational materials to support instructions given orally has been demonstrated to largely increase patient understanding [13], particularly, when the target audience was mostly low-literate readers [14],[15]. Low literacy is negatively related to chronic disease management including T2D, hypertension and asthma [15].

However, the common characteristics of available diabetes leaflets are generally as follows:

- The content consisted of a small amount of information written in one leaflet, and was mostly confined to the definition, signs and symptoms, complications, and the four pillars of diabetes management, i.e.: education, medication, meal planning and exercise. Sometimes, a detailed diabetes meal planning was included or provided in a separate leaflet.

- The information was written only in texts with no or limited graphics.

- The information was printed in small fonts ( $\leq 12$ font).

- The leaflets were often printed in black ink on standard white or colour printing paper of 70 grams per square metre (gsm) or were simply photocopied.

Diabetes education materials which provide comprehensive information on T2D were rarely found in primary health care facilities. Therefore, there was a great need for developing new, comprehensive diabetes education materials written in Bahasa Indonesia for low-literate readers to be provided in stuctured diabetes education programs as research interventions in primary care.

\section{RESEARCH METHOD}

\subsection{Procedure}

To communicate effectively with low-literate readers, the new diabetes education materials should be developed short and simple with culturally sensitive graphics that encourage desired behaviors [13]. According to National Cancer Institute (NCI), developing effective print materials for low-literate readers involves five standard steps [14], as presented in Table 1. 
Table 1. Summary of the guidelines for developing effective print materials for low-literate readers [14]

The five standard steps in developing print materials:

Step 1: Define the target audience

Step 2: Conduct target audience research

Step 3: Develop a concept for the product

Step 4: Develop content and visuals

Step 5: Pre-test and revise draft materials

Step 1: Define the target audience

Common characteristics of low-literate readers:

- Tendency to think in concrete rather than abstract terms

- Literal interpretation of information

- Insufficient language fluency to comprehend and apply information from written materials

- Difficulty with information processing, such as reading a menu, following medical instructions, or reading a prescription label

Step 2: Conduct target audience research

Information needed about the audience:

- Age, sex, ethnicity, income, education levels, places of work and residence

- Causative/ preventive behaviours related to the topic

- Related knowledge, attitudes and practices

- Patterns of use of related services

- Cultural habits, preferences, and sensitivities related to your topic

- Barriers to behaviours of change

- Effective motivators (e.g. benefits of change, fear of consequences, incentives, or social support)

Step 3: Develop a concept for the product

Five principles for developing the concept for a low-literacy publication:

- Define the behavioural objective(s) of the material

- Determine the key information points the reader needs to achieve the behavioural objective(s)

- Select the most appropriate presentation methods (e.g. audio, audiovisual, print, radio, TV, interactive computer programmes

- Decide on the reading level for the material if you select a print presentation

- Organize topics in the way the person will use them

Step 4: Develop content and visuals

Checklist for key principles of effective low-literacy print materials include content/ style, layout and visuals as follows:

Content/Style:

- The material is interactive and allows for audience involvement

- The material presents "how-to" information

- Peer language is used whenever appropriate to increase personal identification and improve readability

- Words are familiar to the reader. Any new words are defined clearly

- Sentences are simple, specific, direct, and written in the active voice

- Each idea is clear and logically sequenced (according to audience logic)

- The number of concepts is limited per piece

- The material uses concrete examples rather than abstract concepts

- The text highlights and summarizes important points

Layout:

- The material uses advance organizers or headers

- Headers are simple and close to text

- Layout balances white space with words and illustrations

- Text uses upper and lower case letters

- Underlining or bolding rather than all caps give emphasis

- Type style and size of print are easy-to-read; type is at least 12 point

Visuals:

- Visuals are relevant to text, meaningful to the audience, and appropriately located

- Illustrations and photographs are simple and free from clutter and distraction

- Visuals use adult rather than childlike images

- Illustrations show familiar images that reflect cultural context

- Visuals have captions. Each visual illustrates and is directly related to one message

- Different styles such as photographs without background detail, shaded line drawings, or simple line drawings, are pretested with the audience to determine which is understood best

- Cues, such as circles or arrows point out key information

- Colours used are appealing to the audience (as determined by pretesting)

Step 5: Pre-test and revise draft materials

Key issues to probe for pretesting include:

Comprehension:

- Important aspects include:

- Suitability of the words used?

- Distinguishing key details?

- Meaning or relationship of visuals to text?

IJPHS Vol. 5, No. 1, March 2016 : 16-26 
Attraction:

- What kind of feelings does the material generate? Enthusiasm? Just OK? Or a "turnoff”?

Acceptability:

- Compatibility with local culture?

- Supportive of ethnic practices?

- Suitability for both sexes and all ages?

- Personal involvement or relevance?

Note. Adapted from "Clear \& simple: Developing effective print materials for low-literate readers" by National Cancer Institute (NCI). Bethesda: National Institutes of Health NCI; 2003 [updated 27 February 2003]. Available from: http://www.cancer.gov/cancertopics/cancerlibrary/clear-and-simple.

There are several tips for writing low literacy materials as described by Miller (2001) [16], and by Potter and Martin (2005) [17]. They are presented in Table 2 and Table 3.

Table 2. Quick tips for writing low literacy materials [16]

- $\quad$ Keep writing style simple

- Use active voice and conversational style

- Sequence main points in a logical manner

- Make you sub-points clearly correspond to the main point

- Use short words and sentences

- Avoid double negative expressions

- Use the same word consistently rather than synonyms to avoid confusion

- For lengthy materials, use a table of contents to point the way

- Write short summaries at the end of long sections

- Use a larger type than 12 points for the text

- Enlarge or bold the type in headings and sub-headings

- Use extra white space to separate sections

- Use age appropriate illustrations

- Place illustrations close to the related text

- Use simple grids, site maps, and other visuals to ease the reading of the text

Note. Adapted from "How to write low literacy materials" by Miller JE. Journal of Extension. 2001;39(1).

Epub February 2001.

Table 3. The most helpful written materials for all users, especially poor readers [17]

- Emphasize the desired behavior rather than medical facts. Education is more important than information

- Have just one or two educational objectives - what the reader needs to learn and do

- Use clear headings and bullets, instead of paragraphs, and ample white space

- Use short sentences, active voice and conversational language

- Use pictures and examples to illustrate important points

- Supplement written materials with conversation, video and audio sources

Note. Adapted from "Health literacy fact sheets" by Potter L\& Martin C. Hamilton, New Jersey: Centre for

Health Care Stategies, Inc; 2005 [updated August 2005]. Available from:

http://www.chcs.org/publications3960/publications_show.htm?doc_id=291711.

Generally, in developing the new diabetes education materials, the researcher tried to follow the above guidelines presented in Table 1-3 as much as possible. In contrast to the existing diabetes leaflets which generally look mundane, the new diabetes leaflets were developed to attract and engage patients with T2D. The researcher hired a graphic designer who was also a medical doctor.

There were several characteristics of patients with T2D attending diabetes education programs in primary health care facilities that were taken into account when developing these diabetes leaflets, including: (1) many of them were elderly people who might have difficulty in reading small prints; and (2) majority of them had low education levels (primary school), and thus might need information written in a simple language and supported with a lot graphics to make it easier for them to absorb the information. In order to make the diabetes leaflets look as interesting and eye-catching as possible, while also taking into account these factors, the leaflets were developed as follows: (1) written in a simple language and supported with colorful graphics; (2) printed in large font size i.e. Arial 14; and (3) printed on colorfully glossy and thick A4 sized printing papers with $170 \mathrm{gsm}$.

The guidelines suggest that the number of concepts and educational objectives should be limited, and the desired behaviors should be emphasized rather than the medical facts [14],[17]. However, these rules were not completely followed due to several considerations which include: (1) limited information on the

Developing Comprehensive Diabetes Education Materials for Structured .... (Oryzati Hilman Agrimon) 
existing diabetes leaflets available, and (2) the research participants previously had very little access of diabetes information and education. Therefore, for the particular purpose of providing comprehensive information on T2D to patients with T2D, the researcher opted to include a large amount of information the new diabetes leaflets. The researcher thus developed nine diabetes leaflets and one diabetes bookletas follows:

- Leaflet 1 : "Recognise Diabetes Mellitus and Act on it"

- Leaflet 2 : "Meal Planning for Diabetics 1"

- Leaflet 3 : "Meal Planning for Diabetics 2"

- Leaflet 4 : "Meal Planning for Diabetics 3"

- Leaflet 5 : "Physical Activity for Diabetics 1"

- Leaflet 6 : "Physical Activity for Diabetics 2"

- Leaflet 7 : "Foot Care And Foot Exercise for Diabetics"

- Leaflet 8 : "Target for Management of Diabetes Mellitus"

- Leaflet 9 : "Seven Successful Steps for Diabetes Self-Care"

- Booklet 1 : "Food Exchanges and Menu for Diabetics"

The nine leaflets were printed in a A4-sized paper folded in three columns and double sided. The booklet was printed in a A-4 sized paper folded in two columns and double sided in eight pages. All nine diabetes leaflets and one booklet are collectively called 'the diabetes leaflets' in this article.

Furthermore, the NCI 2003 guidelines state that the illustrations used should reflect culturally familiar images [14]. However, this was not possible to follow. Since culturally relevant materials were scarce, most of the graphics used for the new leaflets were downloaded from the internet, which were mostly from Western cultures. These Westernized graphics were inevitably included in the new leaflets. Designing culturally relevant graphics specifically for the new diabetes leaflets would require more time and resources. However, for furtherroll-out of the diabetes leaflets in the future, the Westernised graphics will bechanged to depict Indonesian people.

According to the NCI 2003 guidelines, the reading level for the education materials should be determined. The reading level refers to the number of education years required for a reader for understanding a written passage. Experts' suggestions for this reading level include: (1) aiming for a level that is two to five grades lower than the highest average grade the audience achieved to justify a probable decline in reading skills over time; and (2) a third to fifth grade level is generally appropriate for low-literate readers [14]. To estimate reading level, readability formulas are usually used, such as the Flesch Reading Ease, the FleschKinkaid Grade Level, the Fog Scale, and the SMOG Index [14],[16]. However, these readability formulas are specifically designed and used for English texts, and cannot be used for other languages. Furthermore, there are no such readability formulas in Bahasa Indonesia. Therefore, the reading level for these diabetes education materials could not be determined.

In addition, 14 diabetes posters were developed for teaching aids in diabetes structured patient education sessions. The content of the posters was taken from the corresponding diabetes leaflets focusing on the most important issues with fewer words and more pictures. The posters were printed in colorful glossy A1-sized printing papers with special outdoor material. The diabetes posters developed are entitled as follows:

- Poster 1 : "What Happens in Type 2 Diabetes? Mechanism of Insulin"

- Poster 2 : "Risk Factors of Type 2 Diabetes"

- Poster 3 : "Symptoms of Type 2 Diabetes"

- Poster 4 : "Hypoglycaemia"

- Poster 5 : "Hyperglycaemias"

- Poster 6 : "Complications of Type 2 Diabetes"

- Poster 7 : "Management of Type 2 Diabetes"

- Poster 8 : "Meal Planning for Diabetics"

- Poster 9 : "Balanced Diet for Diabetics"

- Poster 10 : "Portion Control for Diabetics"

- Poster 11 : "Physical Activity for Diabetics"

- Poster 12 : "Targets of Type 2 Diabetes Management"

- Poster 13 : "Foot Care for Diabetics"

- Poster 14 : "Diabetes Self-Management"

These fourteen diabetes posters were also reproduced in $\mathrm{x}$-banner compositions for display in the function room during diabetes education programs. The goal was to help getting the message of diabetes information taught across more effectively. 
Due to limited time and resources, pretesting was conducted to only five members of the intended target audience, i.e. adults with T2D [14]. Each individual was shown draft materials of diabetes leaflets in a short individual interview for a simple readability test and inputs on comprehension, attraction and acceptability. The draft designs were also distributed to five general practitioners to obtain broader perspectives. The majority of them gave positive inputs on comprehension, attraction and acceptability. There were only minor inputs, particularly on the layout, colours and use of graphics. The draft materials were revised based on the inputs obtained. Lastly, the final designs diabetes leaflets, posters and x-banners were printed at a printing shop.

A large amount of information on T2D was included in the diabetes leaflets to provide comprehensive information to the research participants. However, these might be overwhelming and discouraging for them. The use of westernised graphics in the leaflets might also be distracting or intimidating. The readability test to determine the reading level was not conducted that might result in higher reading level for the research participants. In order to find out about the participants' feedback about the leaflets and to obtain suggestions for improving the leaflets in the future, an evaluation of the diabetes leaflets was conducted.

\subsection{Sample}

The new diabetes leaflets were then distributed to 88 people with T2D who attended two diabetes education programs as research interventions in primary health care facilities in Yogyakarta City. Each participant received a whole set of 10 leaflets. After reading the diabetes leaflets, the particpants were asked to complete an evaluation of the leaflets through an anonymous one-page evaluation form.

\subsection{Evaluation of diabetes leaflets}

The evaluation consisted of four items using a rating scale of 1 to 10 provided in each question with the explanation of the meaning, and one open-ended question as shown in Table 4.

Table 4. Evaluation of the diabetes leaflets

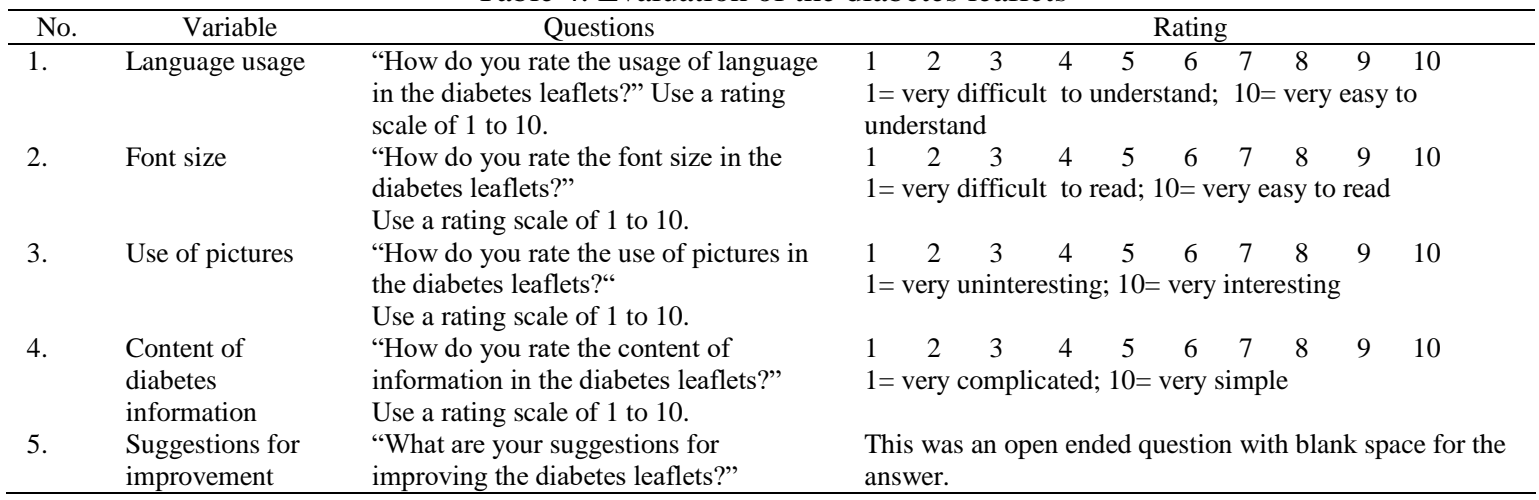

\section{RESULTS AND ANALYSIS}

Descriptive statistics were used to analyze the results. For the first four questions, majority of the participants $(87.2 \%-95.4 \%)$ rated the diabetes leaflets and booklet in the range of 7-10, while only a few $(4.6 \%-10.5 \%)$ rated in the range of 5-6 and none rated $<5$. Most participants considered that the diabetes leaflets were easy to understand, easy to read, interesting, and simple. For question no.5, the majority of the participants $(79.7 \%)$ gave general comments on what they thought about the leaflets without providing suggestions for improvement. The most common statement was: "The diabetes leaflets are already good and easy to understand". Around one third of the participants also gave suggestions for improvement. Results of the evaluation of the leaflets are presented in Table 5. 
Table 5. Results of the evaluation of diabetes leaflets $(n=88)$

Evaluation Q
1. How do you rate the usage of
leaflets?
$1=$ very difficult to understand
$10=$ very easy to understand

\section{How do you rate the font size in the diabetes leaflets?}

$$
\begin{aligned}
& 1=\text { very difficult to read } \\
& 10=\text { very easy to read }
\end{aligned}
$$

\section{How do you rate the use of pictures in the diabetes} leaflets?

$$
\begin{aligned}
& 1=\text { very uninteresting } \\
& 10=\text { very interesting }
\end{aligned}
$$

\begin{tabular}{|c|c|c|}
\hline ating & Total Chosen & Percentage \\
\hline 1 & - & - \\
\hline 2 & - & - \\
\hline 3 & - & - \\
\hline 4 & - & - \\
\hline 5 & $5 / 88$ & $5.7 \%$ \\
\hline 6 & $5 / 88$ & $5.7 \%$ \\
\hline 7 & $17 / 88$ & $19.3 \%$ \\
\hline 8 & $27 / 88$ & $30.7 \%$ \\
\hline 9 & $10 / 88$ & $11.4 \%$ \\
\hline 10 & $24 / 88$ & $27.3 \%$ \\
\hline 1 & - & - \\
\hline 2 & - & - \\
\hline 3 & - & - \\
\hline 4 & - & - \\
\hline 5 & $5 / 88$ & $5.7 \%$ \\
\hline 6 & $4 / 88$ & $4.6 \%$ \\
\hline 7 & $4 / 88$ & $4.6 \%$ \\
\hline 8 & $37 / 88$ & $42.0 \%$ \\
\hline 9 & $14 / 88$ & $15.9 \%$ \\
\hline 10 & $38 / 88$ & $43.2 \%$ \\
\hline 1 & - & - \\
\hline 2 & - & - \\
\hline 3 & - & - \\
\hline 4 & - & - \\
\hline 5 & $2 / 88$ & $2.3 \%$ \\
\hline 6 & $2 / 88$ & $2.3 \%$ \\
\hline 7 & $3 / 88$ & $3.4 \%$ \\
\hline 8 & $31 / 88$ & $35.2 \%$ \\
\hline 9 & $17 / 88$ & $19.3 \%$ \\
\hline 10 & $33 / 88$ & $37.5 \%$ \\
\hline 1 & - & - \\
\hline 2 & - & - \\
\hline 3 & - & - \\
\hline 4 & - & - \\
\hline 5 & $3 / 88$ & $3.4 \%$ \\
\hline 6 & $6 / 88$ & $6.8 \%$ \\
\hline 7 & $24 / 88$ & $27.3 \%$ \\
\hline 8 & $18 / 88$ & $20.5 \%$ \\
\hline 9 & $17 / 88$ & $19.3 \%$ \\
\hline 10 & $20 / 88$ & $22.7 \%$ \\
\hline
\end{tabular}

\section{How do you rate the content of information in the} diabetes leaflets?

$$
\begin{aligned}
& 1=\text { very complicated } \\
& 10=\text { very simple }
\end{aligned}
$$

5. What are your suggestions for improving the diabetes leaflets?"

tes


There was a great need for developing new diabetes leaflets and posters written in Bahasa Indonesia in order to provide comprehensive information on type 2 diabetes (T2D) through diabetes education programs [7]. While most diabetes education materials available provide too much information, present overly complex concepts and use language for high-literate individuals [18], in developing the new diabetes education materials, the researcher tried to follow guidelines on developing print materials for low-literate readers [14],[16],[17] as much as possible.

However, not all rules could be well followed, particularly on the amount of information and educational objectives written, the use of culturally familiar illustrations, and determining the reading level. There was a lot of information on T2D included in the new diabetes leaflets that might be overwhelming and discouraging for the research participants. The westernised pictures and graphics downloaded from the internet were inevitably used in the leaflets that might be distracting and intimidating. Producing new pictures and graphics with local content and people would require more time and resources. The readability test to determine the reading level was not conducted due to the unavailability of any reading formula for use in Bahasa Indonesia. This might have resulted in higher reading level for the research participants. All of these were the limitations in developing the new diabetes education materials, which were mostly related to limited time and resources.

In order to find out about the participants' feedback about the leaflets and to obtain suggestions for improving the leaflets in the future, an evaluation of the diabetes leaflets was conducted. The evaluation consisted of 5 items including language use, font size, use of pictures, content of information and suggestions for improvement in the future. The participants highly favored the diabetes leaflets and gave high ratings on all evaluation items. They indicated that the diabetes leaflets were easy to understand, easy to read, interesting, and simple. This might due to the following reasons: (1) Diabetes leaflets were rarely found in primary health care facilities in Yogyakarta City; (2) Patient education on diabetes was not routinely conducted by health care providers in primary health care facilities; (3) It was the first time for all participants to receive diabetes leaflets, thus they were very excited about the leaflets; (4) Above all, the participants received not only one mundane diabetes leaflet, but "a set of colorful leaflets with such comprehensive information", which increased their enthusiasm about the leaflets. They were pleased to obtain handy comprehensive information on diabetes which they could refer to anytime. They even asked for more leaflets to be distributed to their family members, relatives and friends who also had T2D hoping that others also may know their illness better.

The diabetes leaflets were very well received and highly appreciated by all participants. Instead of giving suggestions, the majority of the participants also gave very positive statement about the leaflets. The participants indicated that getting "a set of colorful leaflets with such comprehensive information" was much beyond their previous expectation or imagination. This was clearly pointed out by some participants in the following words: 'complete', 'perfect', 'more than enough', 'providing good information', 'encouraging for discipline and fighting spirit, and 'increasing my diabetes knowledge'. More than one-third of the participants several suggestions for improving the diabetes leaflets in the future.

There were valuable suggestions provided by the participants for improving the diabetes leaflets in the future. Developing new diabetes education materials for research interventions was an initial step for developing these materials for broader diabetes communities. These suggestions were therefore essential for developing the revised diabetes leaflets in the future.

The most frequent suggestion was "the need for compiling all the diabetes leaflets into one book" so that it could serve as a complete guide book and reminder for diabetics; because it would make the leaflets orderly, handy to carry, easy to read and not easily lost. This was indeed a smart suggestion. However, developing a complete guide book for free distribution will be very costly and the idea of reading the whole complete guide book might not make it practical to read particularly for poor readers. Nevertheless, a simple diabetes handbook containing simple instructions on the five principles of diabetes management and other essential diabetes self-management behaviors might be useful for people with T2D. This handbook should also contain value targets of clinical outcomes to be achieved, such as HbA1c, fasting blood glucose, twohour postprandial plasma glucose, total cholesterol, LDL cholesterol, HDL cholesterol, triglycerides, blood pressure, body mass index and waist circumference. Furthermore, this handbook can be provided with blank spaces to record the results of clinical outcomes from regular examinations thus can indicate whether the diabetes is well or poorly controlled. This diabetes handbook will therefore have double functions: as a diabetes education material as well as serving as a diabetes record book which should be brought every time the diabetic goes to see health care providers. A sample of this diabetes record book is "Diabetes SelfManagement Clinical data Record Book" developed by Australian Disease Management Association [19]. Hopefully, this double function diabetes handbook can increase the diabetic's insight and awareness of the disease, its management and diabetes self-care practices. Meanwhile, loose diabetes leaflets with different 
topics are still needed to provide longer description of each topic. A combination of a simple diabetes handbook and various diabetes leaflets should be made available for free distribution for the general public.

Another frequent suggestion was "the need for broader distribution of the leaflets", not only in other surrounding primary health care facilities, but also in other parts of Indonesia so that others might have the same opportunity to engage actively with the management of the disease. The research participants clearly noticed the usefulness of having diabetes leaflets in hand and wanted the leaflets to be disseminated to broader diabetes communities. This was very much in line with the goal and expectation of the researcher. However, there was another possibility of conducting broader distribution of the diabetes leaflets. Considering that the leading diabetes organizations in Indonesia do not have website or do not provide diabetes education materials in their websites, developing a website for providing diabetes education materials to be downloaded for free will be very useful for the general public.

In order to do develop a simple diabetes handbook and various diabetes leaflets for free distribution and a website for providing free downloadable diabetes education materials, a lot of support and resources from the government and other relevant organizations are required. Advocacy to the Republic of Indonesia Department of Health and local health offices on developing diabetes education materials and structured diabetes education programs, and writing proposals for international grants on these topics should be conducted.

Although majority of the participants highly favored the diabetes leaflets, there were a few participants who still considered that the content of information could be improved with simpler language and more pictures. In particular two reasons were identified, including: the problem of understanding the content of information, and limited education/ supervision from health care providers. The problem of understanding the content of information might be related to the education level of the participants the majority of whom have primary school education level.

Other suggestions for improving the diabetes leaflets include: (1) Give more examples of problem solving for living with diabetes; (2) Incorporate psychological and spiritual aspects; and (3) Give more samples of simple and affordable menus for people with T2D. Some of these suggestions were already included during discussions in the structured group education program sessions, but not yet written in the leaflets, or already included in the leaflets but with little information.

The structured diabetes education program was conducted using a biopsychosocial approach where the educator explored various biopsychosocial problems faced by the participants then discussed the problems and provided some problem solving skills. Diabetics continuously face situations and problems that require them to make quick and informed decisions on adjusting their food, activity and medications [20]. Situations and problems such as a very high or low blood sugar episode, a sick day, performing a religious fasting for 13 hours (for Moslems), other physical problems, emotional problems, social problems, and management strategies were discussed in the structured patient education sessions. Some problem solving for hyperglycaemia and hypoglycaemia were included in the leaflet entitled "Recognize Diabetes Mellitus and Act on It". Some information about problem solving was also included in the leaflet entitled "Seven Successful Steps of Diabetes Self-Care", however there were no examples of problem solving in the leaflet. Incorporating a number of actual examples of problem solving in the revised leaflets will be useful for diabetics as a quick reference for solving particular problems.

Discussions about biopsychosocial problems and problem solving skills during the structured diabetes education programme sessions also included spiritual aspects since religion plays a major role in the everyday life of Indonesian people. According to International Religious Report 2010 on Indonesia, there are a number of religions practiced in Indonesia i.e. Islam (88\%), Protestantism (6\%), Catholicism (3\%), Hinduism (2\%), and others including Buddhism, traditional indigenous religions, Jewish and other Christian denominations $(<1 \%)$ [21]. The collective influence of religions is significantly manifest in the country's political, economic and cultural life. Religion fundamentally inspires the Indonesian public life, as illustrated in the state foundation, Pancasila, which begins with the principle of 'One Godhead'. Pancasila, which means the five pillars, consists of Belief in One God, Humanitarianism, National Unity, Representative Democracy and Social Justice [22]. However, description of spiritual aspects was not included in the leaflets. Incorporating spiritual aspect across faiths in the revised diabetes leaflets in the future will accommodate the needs of Indonesian pataients with T2D more comprehensively.

Meanwhile, some simple menus for diabetics were included in the diabetes booklet on entitled "Food Exchanges and Menu". However the menu samples written in the booklet only consists of 3 meals and 3 snacks for one day. Providing more samples of simple and affordable menus in the leaflets will be more useful for diabetics for encouraging more ideas in food preparation and meal planning. All the above suggestions will be considered to be incorporated into the revised diabetes leaflets to be developed in the future.

IJPHS Vol. 5, No. 1, March 2016 : 16-26 
Another suggestion which emerged from the evaluation was "developing a VCD/DVD on foot exercise". Developing a lively audio-visual media on foot exercise will provide a useful resource for diabetics to follow than just looking at the paper-based instructions and illustrations of foot exercise in the leaflet. Developing a VCD/DVD on foot exercise will be included into the plan of writing proposals for international grants on developing the revised diabetes education materials and establishing structured diabetes education programs in the communities. The last suggestion which emerged from the evaluation, and certainly not the least, was "a call for health care providers to conduct adequate patient education to patients with T2D”.

\section{CONCLUSION}

Diabetes education materials providing comprehensive information on T2D were rarely found in primary health care facilities in Yogyakarta City. Developing new, comprehensive diabetes education materials written in Bahasa Indonesia for low-literate readers was greatly needed for conducting stuctured diabetes education programs in primary care. These materials consisted of a set of diabetes leaflets ( 9 leaflets and 1 booklet) for distribution to participants, and 14 diabetes posters and banners for teaching aids during diabetes education program sessions. The diabetes leaflets developed were very well received and highly appreciated by the participants. There were a number of suggestions provided by the research participants for improving the diabetes leaflets in the future, most importantly compiling the diabetes leaflets into one book as a diabetes guide book and broader distribution of the diabetes leaflets to all parts of Indonesia.

\section{ACKNOWLEDGEMENTS}

This work was jointly funded by Faculty of Medicine \& Health Sciences and Asri Medical Center, University of Muhammadiyah Yogyakarta, Yogyakarta, Indonesia.

\section{REFERENCES}

[1] WHO/SEARO, "Noncommunicable diseases in South-East Asia region", New Delhi, World Health Organization Regional Office for South-East Asia, 2002.

[2] Wild S., Roglic G., Green A., Sicree R., King H., "Global prevalence of diabetes: estimates for the year 2000 and projections for 2030”, Diabetes Care, vol/issue: 27(5), pp. 1047-53, 2004. PubMed PMID: 15111519.

[3] International Diabetes Federation (IDF), " Diabetes atlas", Brussels, IDF, 2006.

[4] WHO, "Innovative care for chronic conditions: Building blocks for action - Global report", Geneva, Noncommunicable Diseases and Mental Health World Health Organization, 2002.

[5] Tang TS., Funnell MM., Anderson RM., "Group Education Strategies for Diabetes Self-Management", Diabetes Spectrum, vol/issue: 19(2), 2006.

[6] International Diabetes Foundation (IDF), "Position statement: Self-management education - Diabetes selfmanagement education: A right for all”, IDF, 2011. [30 March 2012]. Available from: www.idf.org/print/education/position-statement/self-management-education.

[7] Colagiuri R., Girgis S., Eigenmann C., Gomez M., Griffiths R., "National evidence based guideline for patient education in type 2 diabetes", Canberra, Diabetes Australia and the NHMRC, 2009.

[8] Loveman E., Frampton GK., Clegg AJ., "The clinical effectiveness of diabetes education models for Type 2 diabetes: a systematic review", Health Technol Assess, vol/issue: 12(9), pp. 1-116, 2008. PubMed PMID: 18405469.

[9] Funnell MM., Anderson RM., Arnold MS., Barr PA., Donnelly M., Johnson PD., et al., "Empowerment: An idea whose time has come in diabetes education", The Diabetes Educator, vol/issue: 17(1), pp. 37-41, 1991.

[10] Goldstein M., (editor), "Promoting self-management in primary care settings: Limitations and opportunities a commentary", U.K., John Wiley \& Sons, Ltd, 2002.

[11] Clement S., "Diabetes self-management education", Diabetes Care, vol/issue: 18(8), pp. 1204-14, 1995.

[12] Johnson JA., "Self-efficacy theory as a framework for community pharmacy based diabetes education programs", The Diabetes Educator, vol. 22, pp. 237-41, 1996.

[13] Mayeaux EJ., Peggy WM., Arnold C., Davis TC., Jackson RH., Sentell T., "Improving patient education for patients with low literacy skills", American Family Physicans, vol/issue: 53(1), pp. 205-11, 1996.

[14] National Cancer Institute (NCI), "Clear \& simple: Developing effective print materials for low-literate readers", Bethesda, National Institutes of Health NCI, 2003. [updated 27 February 2003; cited 2012 19 July]. Available from: http://www.cancer.gov/cancertopics/cancerlibrary/clear-and-simple.

[15] Wallace SL., Lennon SE., "American Academy of Family Physicians patient education materials: Can patients read them?”, Family Medicine Journal, vol/issue: 36(8), pp. 571-4, 2004.

[16] Miller JE., "How to write low literacy materials", Journal of Extension, vol/issue: 39(1), 2001.

[17] Potter L., Martin C., "Health literacy fact sheets", Hamilton, New Jersey, Centre for Health Care Stategies, Inc, 2005. [updated August 2005; cited $2012 \quad 20$ July]. Available from: http://www.chcs.org/publications3960/publications_show.htm?doc_id=291711. 
[18] Kandula NR., Nsiah-Kumi PA., Makoul G., Sager J., Zei CP., Glass S., et al., "The relationship between health literacy and knowledge improvement after a multimedia type 2 diabetes education program", Patient Educ Couns, vol. 75, pp. 321-7, 2009.

[19] Australian Disease Management Association (ADMA), "Diabetes self-management: Clinical data record book Caulified", Victoria, ADMA, 2008. [updated 11 November 20088 August 2011]. Available from: http://clearinghouse.adma.org.au/browse-resources/patient-client-education-material/data-record-book-finalcopy/details.html.

[20] American Association of Diabetes Educators (AADE), “AADE 7 self-care behaviors: Measurable behavior change is the desired outcome of diabetes education Chicago, AADE, 2012. [3 July 2012]. Available from: http://www.diabeteseducator.org/ProfessionalResources/AADE7/.

[21] U.S. Department of State Bureau of Democracy Human Rights and Labor, "International Religious Freedom Report 2010: Indonesia", Washington DC, U.S. Department of State, 2010.

[22] Hosen N., "Religion and the Indonesian Constitution: A Recent Debate", Journal of Southeast Asian Studies, vol/issue: 36(3), pp. 419-40, 2005.

\section{BIOGRAPHIES OF AUTHORS}

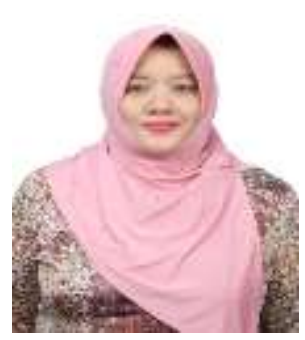

Dr. Oryzati Himan-Agrimon is a senior lecturer at Department of Family Medicine and Public Health, School of Medicine, Faculty of Medicine and Health Sciences, UniversitasMuhammadiyah Yogyakarta (UMY), Indonesia. She is also a manager of education and research affairs at UMY Firdaus Primary Care Clinic. At the national level, she belongs to the National Board of Primary Care Physicians, a task force responsible for preparing a prostgraduate medical eduation for primary care physicians (DLP) in Indonesia. She obtained her medical doctor degree from Faculty of Medicine, Gadjah Mada University, Yogyakarta, Indonesia in 1997. She continued a postgraduate study at College of Medicine, University of the Philippines Manila funded by UMY Faculty of Medicine and Health Sciences. She obtained her master degree in Master of Science in Clinical Medicine - Family Medicine in 2007. She then received a DIKTI scholarship to take a PhD program in General Practice at the the University of Adelaide, Australia and completed the program in 2014. Her professional areas of interest include Family Medicine/ General Practice, Patient Education and Counseling, Medical Education, Chronic Disease Self-Management, Health Promotion and Disease Prevention, and Complementary and Integrative Medicine. She practices at UMY Firdaus Primary Care Clinic primarily as an educator and counselor.

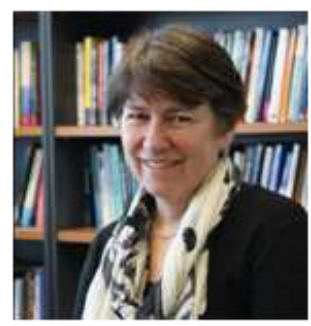

Dr Jackie Street is a Senior Lecturer with a particular interest in community engagement to inform policy and practice. In 2012-15 she held an Australian National Preventive Health Agency Fellowship. She oversees the HealthyLaws and HealthyViews projects. From 20092015 she was a Team Investigator on the NHMRC Capacity Building Grant, Health Care in the Round. She holds qualifications and has research and teaching experience in public health and biochemisty. Some her current projects: HealthyLaws and HealthyViews: ANPHA funded projects examining Indigenous and non-Indigenous community perspectives on the use of laws and regulation to address childhood obesity; The Well Child: a systematic review of prevalence of overweight and obesity in Indigenous Australian children and development of appropriate responses in an Indigneous context; Community participation in decision making in policy and health technology assessment; and Healthcare in the round: Building capacity in health services research across disciplines 